\title{
Loss of SIM2s inhibits RAD51 binding and leads to unresolved replication stress
}

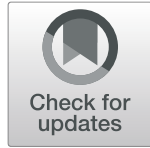

Scott J. Pearson' ${ }^{1}$, Jessica Elswood ${ }^{1}$, Rola Barhoumi ${ }^{1}$, Brittini Ming-Whitfield ${ }^{2}$, Monique Rijnkels ${ }^{1}$ and Weston W. Porter ${ }^{1,3^{*}}$ (D)

\begin{abstract}
Background: Mutations in genes associated with homologous recombination (HR) increase an individual's risk of developing triple-negative breast cancer (TNBC). Although known for their role in repairing dsDNA breaks, HR repair elements also stabilize and restart stalled replication forks. Essential to these functions are RAD51 and its paralogs, each of which has a unique role in preventing replication fork collapse and restart. However, progress toward understanding the regulation of these factors has been slow. With such a pivotal role in the maintenance of genomic integrity, furthering our understanding of this pathway through the discovery of new factors involved in HR is important. Recently, we showed that singleminded-2s (SIM2s) is stabilized in response to dsDNA breaks and is required for effective HR.
\end{abstract}

Methods: Initial analysis of the effect loss of SIM2s has on replication stress resolution was conducted using DNA combing assays in established breast cancer cell lines. Further analysis was conducted via immunostaining to determine the effect loss of SIM2s has on factor recruitment. In vivo confirmation was achieved through the use of a mammary epithelial cell conditional knockout mouse model before SIM2s' role in RAD51 recruitment was determined by immunoblotting.

Results: Here, we show loss of SIM2s decreases replication fork stability, leading to fork collapse in response to genotoxic stress. Furthermore, loss of SIM2s results in aberrant separation of sister chromatids during mitosis, which has been previously shown to result in chromosomal fragmentation and aneuploidy. Interestingly, loss of SIM2s was shown to result in failure of RAD51 to localize to sites of replication stress in both breast cancer cell lines and primary mammary epithelial cells. Finally, we observed SIM2 is stabilized in response to genotoxic stress and interacts with RAD51, which is necessary for RAD51-DNA binding.

Conclusions: Together, these results show a role for SIM2s in the resolution of replication stress and further characterize the necessity of SIM2s for effective RAD51 loading in response to DNA damage or stress, ultimately promoting genomic integrity and thus preventing the accumulation of cancer-promoting mutations.

Keywords: Breast cancer, Tumor suppressor, Genetic instability, SIM2, Replication stress

\section{Background}

Mutations in components of the homologous recombination (HR) pathway have long been associated with an increased risk of developing breast cancer. More specifically, mutations in the DNA-damage repair (DDR) gene BRCA1 alone can increase the probability of developing

\footnotetext{
* Correspondence: wporter@cvm.tamu.edu

${ }^{1}$ Department of Integrative Biosciences, College of Veterinary Medicine, Texas A\&M University, College Station, TX 77843, USA

${ }^{3}$ Present Address: Veterinary Integrative Biosciences, Texas A\&M University,

College of Veterinary Medicine, College Station, TX 77843, USA

Full list of author information is available at the end of the article
}

breast cancer before the age of 80 from 12 to $75 \%[1,2]$. Moreover, individuals with BRCA1/2 mutations are significantly more likely to develop highly invasive/malignant triple-negative breast cancer (TNBC). In fact, $42 \%$ of breast cancer cases in BRCA1 mutation carriers are TNBC compared to $15-20 \%$ in non-BRCA-mutated breast cancers $[3,4]$. Although this increased risk for TNBC could be attributed to deficiencies in DDR, novel roles for BRCA1 also include the stabilization and resolution of stalled replication forks arising from a multitude of different factors [5]. With the increased instance

(c) The Author(s). 2019 Open Access This article is distributed under the terms of the Creative Commons Attribution 4.0 International License (http://creativecommons.org/licenses/by/4.0/), which permits unrestricted use, distribution, and 
of highly invasive breast cancer in individuals with mutations in BRCA, the identification of other factors that mimic the ability of BRCA1 to maintain genomic stability would expand our repertoire of oncogenic markers and increase our ability to design targeted treatments for breast cancer patients. This would help to define malignancies that are more likely to become invasive and may respond to PARP inhibitor (PARPi) and platinum salt therapeutics, which are becoming the standard of care for individuals with BRCA mutations.

Replication stress can be induced by many different aberrations during DNA replication; however, it can generally be defined as a slowing or stalling of the replication fork complex [6]. Endogenously, replication stress can be caused by unrepaired DNA lesions, ssDNA, unusual DNA structures (such as hairpins and triplexes), transcription, mis-incorporation of nucleotides, and limited resources, to name a few [6]. With many potential causes of replication stress, there is no singular replication stress repair pathway. Interestingly, a common factor in replication stress stabilization and repair after prolonged stalling of replication forks is the accumulation of non-DNAdamage-associated RAD51 and other members of the HR pathway. This suggests a recombination-based attempt to resolve the stalled fork [7-11].

During the $\mathrm{S}$ phase, BRCA1 has been shown to protect stalled replication forks from collapse, preventing dsDNA breaks that can lead to the development of detrimental mutations [10]. Later in the cell cycle during the onset of mitosis, sister chromatids are intertwined and are separated via a topoisomerase II-dependent process [12]. Failure of this process to occur can lead to chromosomal breakages, potentially resulting in aneuploidy or cell death. RAD51 plays a role in this replication process during replication restart after stalling [7]. Early in hydroxyurea (HU)-induced replication stress, low levels of RAD51 are associated with nascent ssDNA at the replication fork in a XRCC3-dependent manner [7]. RAD51 is predicted to play a role in the quick restart of stalled replication forks, as depletion of RAD51 leads to the persistence of stalled forks even after $\mathrm{HU}$ has been removed [7]. However, in cells with forks stalled for longer than $24 \mathrm{~h}$, fork restart does not occur after removal of HU, and instead, RAD51 foci formation occurs. This suggests that after prolonged stress, RAD51 plays a role in the removal and repair of stalled and collapsed forks [7].

Recently, our lab demonstrated a role during HR for singleminded 2s (SIM2s; a short splice variant of SIM2, and the predominant isoform of SIM2 in the mouse mammary gland) $[13,14]$. SIM2s is a member of the basic-helix-loop-helix/PER-ARNT-SIM family of transcription factors. In its role in HR, SIM2 is phosphorylated and stabilized in response to ionizing radiation, which can be abrogated through the mutation of a serine residue located within an ATM (ataxia telangiectasia mutated) consensus site [13]. Loss of SIM2 results in reduced recruitment of RAD51 to sites of DNA damage and, thus, an overall decrease in HR efficiency [13]. In addition to playing a role in HR, loss of SIM2s has been associated with an epithelial mesenchymal transition (EMT) in both normal breast and malignant cell lines [14-20]. Moreover, loss of SIM2 or the introduction of a point mutation at S115, a likely target of ATMdependent phosphorylation, in a xenograft model results in a significant increase in metastasis found within the lung $[13,17]$. Here, we propose a role for SIM2s in maintaining genomic stability by assisting the resolution of prolonged replicative stress.

\section{Methods}

Cell culture

SUM159 and MCF7 cells were obtained from American Type Culture Collection (ATCC) and maintained according to the ATCC guidelines.

\section{Generation of cell lines}

Cell lines were generated as previously described [13]. In brief, SIM2 constructs were generated via long cDNA synthesis. Plasmids were amplified using Subcloning Efficiency $^{\mathrm{Tm}} \mathrm{DH} 5 \alpha^{\mathrm{TM}}$ competent cells (Life Technologies). Plasmid DNA was isolated using the HiPure Plasmid Maxiprep kit (Life Technologies) or the ZymoPURE Plasmid DNA Isolation Kit (Zymo Research). Ten micrograms of plasmid was mixed with GeneJuice (EMD Millipore) in $1 \mathrm{~mL}$ of Opti-MEM (Life Technologies) and incubated at room temperature for $15 \mathrm{~min}$. This mixture was then added onto Phoenix-AMPHO lentiviral packaging cells (ATCC). Cells were incubated for $24 \mathrm{~h}$ at $32{ }^{\circ} \mathrm{C}$ and $5 \% \mathrm{CO}_{2}$. Media was collected and filtered through a $0.45-\mu \mathrm{m}$ filter. The recommended amount of Sequabrene (Sigma) was added to the filtered media. The media was then added to SUM159 cells in six-well plates. Plates were centrifuged at $200 \times g$ for 60 min and allowed to incubate overnight at $32{ }^{\circ} \mathrm{C}$ and $5 \%$ $\mathrm{CO}_{2}$. Media was again collected from the packaging cells the next day, and target cells were transduced a second time, as described above. Puromycin selection $(2 \mu \mathrm{g} / \mathrm{mL})$ was started the following day and maintained for at least a week [14].

\section{Generation of shSIM2 containing cell lines}

MCF7 cells containing shSIM2 were previously established [14]. In brief, the shSIM2 was generated by inserting 5' - GAT CCG GTC GTT CTT TCT TCG AAT TTC AAG AGA ATT CGA AGA AAG AAC GAC CTC TTT TTT GGA AA-3' into pSilencer U6-retro 5.1 shRNA vector (Ambion), and control cells ( $p S I L)$ were generated by inserting a nonspecific scrambled sequence 
into the same vector. Plasmids were then packaged into lentivirus using Phenix HEK293-Ampho packaging cells as previously described [14].

\section{Primary mammary epithelial cell (MEC) isolation}

Primary MECs were isolated from the \#3, \#4, and \#5 mammary gland tissues and placed in wash buffer $(1 \times$ DMEM/F12 (Life Tech), 5\% FBS (Atlanta Biological), $50 \mu \mathrm{g} / \mathrm{mL}$ (Life Technologies)) and mechanically homogenized with \#10 scalpels (Feather). Glands were then placed in $2 \mathrm{mg} / \mathrm{mL}$ Collegenase A (Roche) in wash buffer and incubated at $37^{\circ} \mathrm{C}$ with shaking for $\sim 1.5 \mathrm{~h}$. Organoids were pelleted at $600 \times g$ for $10 \mathrm{~min}$, and supernatant was aspirated. Free nucleic acids were then digested with DNAseI treatment (100 $\mu \mathrm{g} / \mathrm{mL}$ DNAse (Sigma), DMEM/ F12). Organoids were washed in wash buffer four times and subsequently pelleted by pulse spinning at $450 \times g$. Organoids were then digested in $1 \mathrm{mg} / \mathrm{mL}$ trypsin (Life Technologies) at $37^{\circ} \mathrm{C}$ for $\sim 20 \mathrm{~min}$ before being brought up to $10 \mathrm{~mL}$ in growth media (DMEM/F12, 10\% FBS, 100 units $/ \mathrm{mL}$ penicillin/streptomycin (Life Technologies), $5 \mu \mathrm{g} / \mathrm{mL}$ insulin (Sigma), $50 \mu \mathrm{g} / \mathrm{mL}$ gentamicin (Life Technologies), $1 \mu \mathrm{g} / \mathrm{mL}$ hydrocortisone, $10 \mathrm{ng} / \mathrm{mL}$ mouse epidermal growth factor (EGF; Life Technologies)), and single cells were pelleted at $450 \times g$ for $3 \mathrm{~min}$. MECs were washed twice more in growth media and pelleted again. MECs were finally plated on $10-\mathrm{cm}$ tissue culture dishes and cultured at $32{ }^{\circ} \mathrm{C}$ and $5 \% \mathrm{CO}_{2}$.

\section{Antibodies}

Antibodies and concentrations are listed in Additional file 1: Table S1.

\section{DNA combing assay}

DNA combing assays were performed as previously described using IdU (Sigma) and CldU (Sigma) with the indicated modifications in timepoints [21]. In brief, the cells were dosed with the indicated reagents (IdU, CldU, $\mathrm{HU}, \mathrm{DMSO}$ ), at the indicated dosages, for the indicated amounts of time depending on the experiment being conducted. Cells were then washed with PBS and trypsinized and collected in a $15-\mathrm{mL}$ conical tube before being washed again with ice-cold PBS, brought to a concentration of 400 cells $/ \mu \mathrm{L}$ and placed on ice. Two microliters of cells was then pipetted onto a charged microscope slide and allowed to dry almost completely. Fifteen microliters of lysis solution $(0.2 \mathrm{M}$ Tris $\mathrm{pH} 7.4,50 \mathrm{mM}$ EDTA, $0.5 \%$ SDS) was added, and slides were incubated at room temperature for $10 \mathrm{~min}$. Slides were then tilted to a $25^{\circ}$ angle, allowing DNA fibers to run down slide, and allowed to dry completely. DNA was then fixed in a 3:1 methanol to acidic acid solution for $2 \mathrm{~min}$, and then removed and allowed to dry overnight.
The next day, slides were placed at $-20^{\circ} \mathrm{C}$ and incubated for a minimum of $24 \mathrm{~h}$ before proceeding to the next step. Slides were then treated with $2.5 \mathrm{M} \mathrm{HCl}$ for $30 \mathrm{~min}$, washed with $0.1 \%$ PBST (PBS-Tween) for $3 \mathrm{~min}$, and then incubated in PBS two times for 3 min. Slides were blocked in 5\% BSA (bovine serum albumin) for 30 min. DNA was then probed with the indicated primary antibodies for $1 \mathrm{~h}$, before washing two times with PBS for $3 \mathrm{~min}$ each. Finally, a secondary antibody was added and incubated for $1 \mathrm{~h}$. Slides were washed two more times in PBS for 3 min and then images were captured using a Zeiss 780 confocal microscope, and fiber lengths were measured in ImageJ.

\section{Anaphase bridges}

Cells were maintained at $37^{\circ} \mathrm{C}$ and $5 \% \mathrm{CO}_{2}$. First, cells were synchronized using a di-thymidine block. Briefly, cells were incubated in $2 \mathrm{mM}$ thymidine (Cayman Chemical) for $19 \mathrm{~h}$, washed, and cultured again in normal media for $9 \mathrm{~h}$. Afterwards, $2 \mathrm{mM}$ thymidine was reapplied for an additional $17 \mathrm{~h}$. Cells were washed again, and normal media was added for 9 additional hours. Finally, cells were fixed with $4 \%$ paraformaldehyde (Santa Cruz) and stained with Hoescht 33342 (Life Technologies). Images were captured using a Zeiss 780 confocal microscope.

\section{Immunofluorescent (IF) staining of cells}

IF was conducted as previously described [14]. Images were captured using a Zeiss 780 confocal microscope. Quantification of nuclear intensity was done in ImageJ.

\section{Immunostaining of tissue sections}

IF of tissue sections was performed as previously described [20]. Images for analysis were captured on a Zeiss Axio Imager.Z1, and representative images were captured on a Zeiss 780 confocal microscope. Quantification of nuclear intensity was done in ImageJ.

\section{Immunoblotting}

Immunoblotting was done as previously described [13].

\section{Cell fractionation}

Cell fractionation was performed as previously described [22] with the following modification: chromatin was fragmented using a bioruptor pico (Diagenode) with $30 \times$ 1-min sonication intervals.

\section{Co-immunoprecipitation}

All steps were conducted on ice or at $4{ }^{\circ} \mathrm{C}$. All beads were washed three times with five volumes TBS before use. Cells were lysed in RIPA buffer containing $1 \mathrm{mM}$ $\mathrm{Na}_{3} \mathrm{VO}_{4}$ (Sigma) and $1 \mathrm{mM}$ complete ULTRA tablets mini EDTA-free Easy pack (Roche) and agitated for 30 
min prior to centrifugation at $10,000 \times g$ for $10 \mathrm{~min}$. Protein concentrations were determined via DC protein assay (Bio-Rad), and $100 \mu \mathrm{g}$ of protein was added to IgG control beads (Cell Signaling, $5873 \mathrm{~S}$ or $8726 \mathrm{~S}$ ) or $6 \mu \mathrm{g}$ of the indicated antibody before incubating overnight. Magnetic beads (Active Motif, 53,033) were then added to the antibody/protein mixture and allowed to incubate for an additional $4 \mathrm{~h}$. Tubes were then placed on a magnetic separator, and beads were washed three times with TBS before being resuspended and boiled for $5 \mathrm{~min}$ in $2 \times$ Laemmli sample buffer lacking reducing agent. $\beta$ mercaptoethanol was then added, and samples were again boiled for $5 \mathrm{~min}$ before immunoblotting.

\section{RNA isolation and real-time qPCR (RT-qPCR)}

RNA isolation, reverse transcription, and RT-qPCR were performed as previously described [17]. Gene expression was evaluated with the following primers: $\operatorname{Sim} 2 s, 5^{\prime}$-AA CCAGCTCCCATGTTTGAC-3' (forward), 5' -ACTCTGAGGAACGGCGAAAA-3' (reverse) and Actb: 5'-GCA ACGAGCGGTTCC G-3' (forward), 5' -CCCAAGAAGG AAGGCTGGA-3' (reverse). Expression was determined using the $2^{-\Delta \Delta C t}$ method and normalized relative to Actb.

\section{Statistical analysis}

All experiments were done in biological triplicates with technical duplicates at a minimum and repeated three times while scientists were blinded to group identity. Before conducting two-tailed Student's $t$ tests, normal distribution was confirmed, and likelihood ratio and Pearson's statistical test were used for goodness of fit comparisons. Significance was considered at $p<0.05$.

\section{Study approval}

Animal studies were approved by the Texas A\&M University Laboratory Animal Care Committee in accordance with IACUC guidelines.

\section{Results}

Loss of SIM2s leads to an increase in replication fork collapse but does not affect replication restart speed

It has been previously demonstrated that members of the HR DDR pathway are associated with maintaining genomic stability through the resolution of replicative stress [5, 7-11]. Having recently discovered SIM2s as a novel protein involved in HR, we hypothesized that loss of SIM2s (through inclusion of shSIM2) would result in a decrease in genomic stability [13]. To test this, we pulse labeled our previously established MCF7-shSIM2 and MCF7-pSIL-scrambled cell lines with the thymidine analog IdU (5-Iodo-2'-deoxyuridine) for $30 \mathrm{~min}$. Cells were then washed, and the control groups were immediately treated with CldU (5-chloro-2'-deoxyuridine) for the indicated time in order to establish a baseline tract length for unperturbed cells. At the same time, treatment groups were treated with HU (a potent antineoplastic agent that inhibits DNA replication through the inhibition of ribonucleoside diphosphate reductase [RNR]) for $2 \mathrm{~h}$. Finally, treatment groups were pulse labeled for the indicated time with CldU (Fig. 1a) [13, 14]. A minimum of 100 tracts were measured for each group and analyzed for overall length (Fig. 1a). To correct for any differences in replication speed between cells containing shSIM2 and those containing pSIL-scrambled, tract lengths of HU-treated groups were normalized to their untreated, basal counterparts for statistical analysis. Using this method, we were able to assess changes in both replication restart speed and replication fork stability by measuring the IdU and CldU tract lengths, respectively.

We first analyzed the replication restart speed of shSIM2-containing cells by measuring the tract length of CldU. Here, longer tract lengths correlate with a shorter amount of time for replication restart to occur after release from replication stress, as this would allow the cell more time to synthesize nascent DNA and incorporate CldU. Interestingly, when we assessed DNA replication restart $30 \mathrm{~min}$ after $\mathrm{HU}$ release, no visible CldU tracts were observable (data not shown), leading us to extend CldU pulse labeling to $60 \mathrm{~min}$. However, after extending the CldU pulse time, we found no significant change in replication restart between shSIM2 and control groups (Additional file 1: Figure S1 A, B).

Next, we analyzed replication fork stability by measuring the IdU tract length. In the case that replication forks become unstable during $\mathrm{HU}$ treatment, they will collapse, leading to a shortening of the IdU tract. This shortening of the tract length of replicated DNA has been previously attributed to failure of a cell to maintain the stability of the stalled replication fork, leading to its collapse and subsequent re-replication [7]. In this way, we were able to observe a significant decrease in replication fork stability in cells containing shSIM2 by measuring a significant decrease in IdU tract length in these cells after treatment with $\mathrm{HU}$ (Fig. 1b, c).

To confirm this finding, we again pulse labeled MCF7shSIM2 and MCF7-pSIL control cells with IdU for 30 min, and then immediately pulse labeled with CldU for another $30 \mathrm{~min}$ before treating cells for $2 \mathrm{~h}$ with DMSO or $10 \mathrm{mM} \mathrm{HU}$ (Fig. 1d, e). We then measured the length of IdU tracts and CldU tracts that were immediately adjacent to IdU tracts, which eliminated any newly firing forks (Fig. 1f). A slight decrease in IdU replication length was observed in MCF7-shSIM2 cells treated with DMSO, suggesting there may be differences in replication speeds between the two cell lines, which we again corrected for by normalizing the tract length of $\mathrm{HU}$ - 


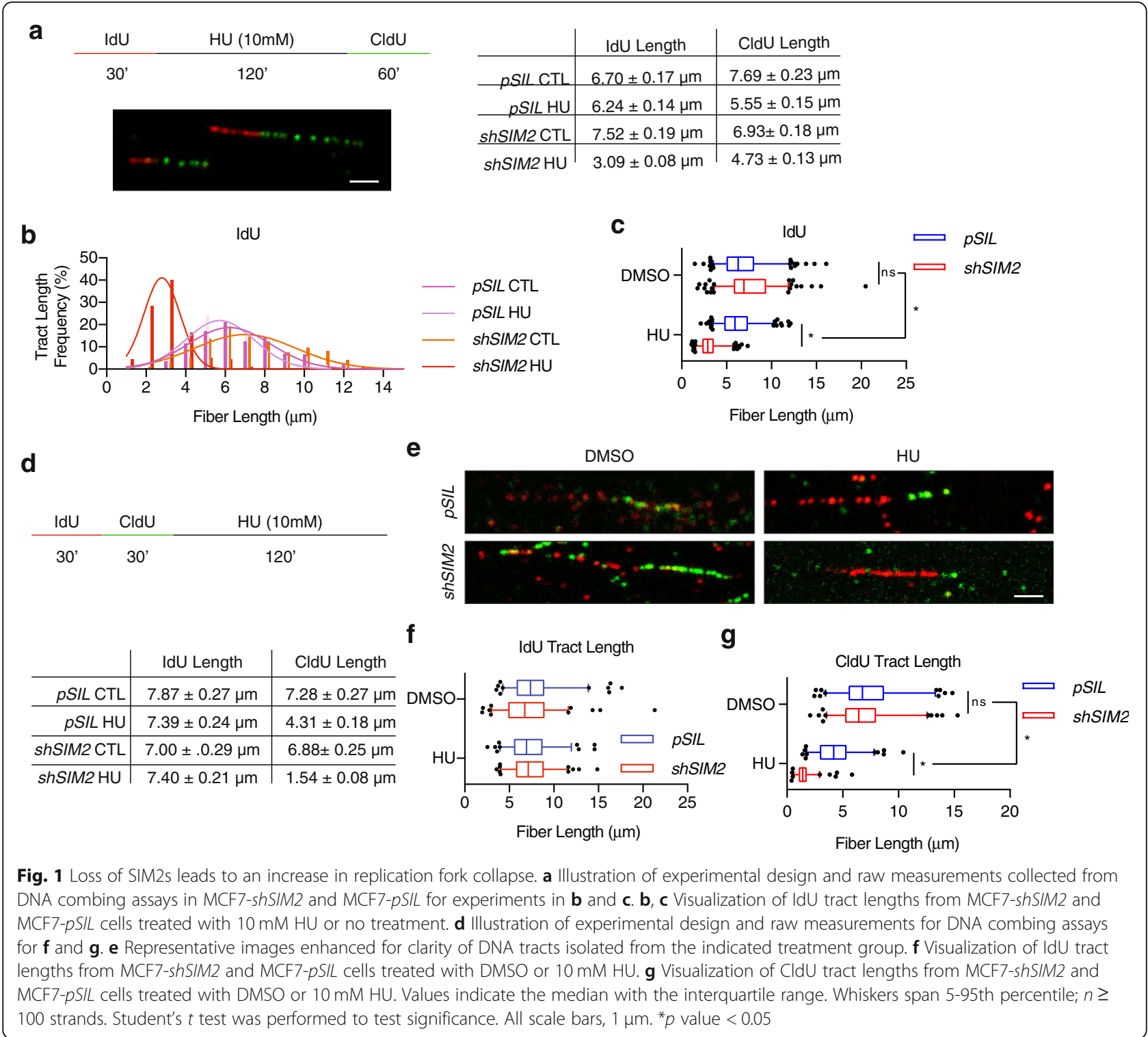

treated groups to their untreated, basal counterparts for statistical analysis (Fig. 1f). Of note, we found a significant decrease in the CldU tract length in MCF7-shSIM2 cells treated with $\mathrm{HU}$, supporting our findings that loss of SIM2 results in a significant increase in replication fork collapse (Fig. 1g).

\section{Loss of SIM2s leads to an increase in stalled forks and newly firing origins}

It has been reported that stalled or collapsed replication forks can lead to formation of a gap between IdU and CldU labeling, possibly due to the firing of a new origin downstream of the stalled fork [23]. Upon measuring the length of gaps between the two pulse labels (from Fig. 1a), we found that, although there is no difference between treated and untreated cells, cells lacking SIM2s had significantly larger gaps than control cells (Fig. 2a, b). As larger gap sizes have been attributed to multiple causes, we next tested MCF7-shSIM2 and control cells for the frequency of elongating replication forks, stalled replication forks, and newly firing origins (Fig. 2a, c) [23]. Cells containing shSIM2 exhibited a higher frequency of both stalled replication forks, as well as an increase in the presence of newly firing replication forks. Both of these findings suggest that loss of SIM2s leads to genomic instability that culminates in the inability to resolve replication stress.

\section{Loss of SIM2s disrupts DNA replication}

To further characterize the effect loss of SIM2s has on replicating cells, we analyzed MCF7-shSIM2 and control cells during anaphase. Previously, it has been shown that 

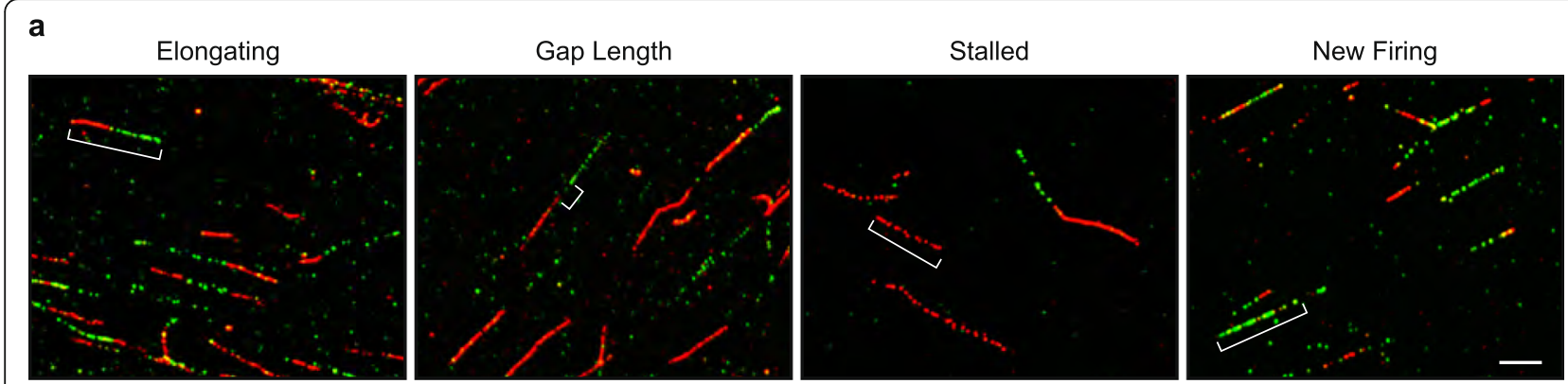

b

C
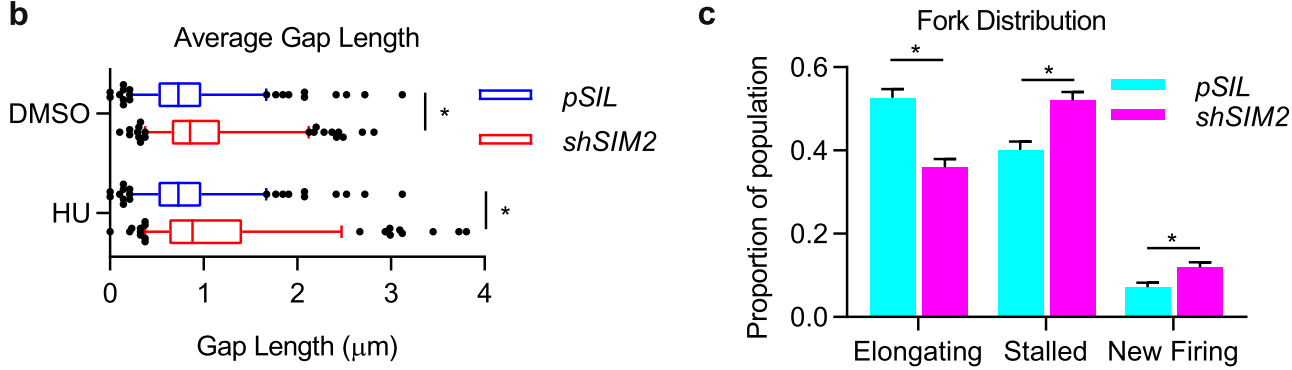

Fig. 2 Loss of SIM2s increases the incidence of aberrations associated with stalled replication forks. a Representative images of DNA combing assays demonstrating the indicated conditions. Scale bar, $2 \mu \mathrm{m}$. b DNA fiber tracts isolated from MCF7 cells that were treated as in Fig. 1a were assessed for the presence of gaps between IdU and CldU tracts. A significant increase in gap length was observed in cells containing shSIM2, with no difference found between no treatment and HU treatment groups. Values indicate the median with the interquartile range. Whiskers span 5-95th percentile; $n \geq 100$ strands. Student's $t$ test was performed to test significance. c Finally, shSIM2 containing cells had lower incidence of actively elongating tracts, with a significant increase in stalled forks and newly firing origins. Likelihood ratio and Pearson's chi-squared tests were performed to test correlations; $n \geq 100$ strands. ${ }^{*} p$ value $<0.05$

loss of factors involved in HR contributes to sisterchromosome non-disjunction, or the inability for sister chromosomes to fully separate during mitosis. Traditional DNA staining is sufficient to reveal these abnormalities, which can present as DNA bridges, lagging strands, or acentric chromosomes (Fig. 3a). After synchronization using a di-thymidine block, cells were stained with Hoechst 33342 and analyzed for the presence of anaphase abnormalities. Here, we observed a significant increase in the fraction of cells containing DNA bridges and lagging strands but not acentric chromosomes in cells containing shSIM2 (Fig. 3b-d).

\section{Loss of SIM2s decreases RAD51 recruitment}

Previous studies have demonstrated that there is significant overlap between DDR pathways and the stabilization and resolution of replication stress [24,25]. With the increase in genomic instability associated with loss of SIM2, we sought to determine if loss of SIM2s correlates with a reduction in DDR factors. To start, we looked at $\gamma \mathrm{H} 2 \mathrm{AX}$ foci formation within the nucleus of MCF7-shSIM2 and MCF7-pSIL cells. As a previous study has demonstrated that $\gamma \mathrm{H} 2 \mathrm{AX}$ levels rise between 16 and $48 \mathrm{~h}$ after $\mathrm{HU}$ treatment, we dosed our cells with $0.5 \mathrm{mM} \mathrm{HU}$ for $24 \mathrm{~h}$ before fixation and immunofluorescent staining [24]. Interestingly, we observed a significant increase in $\gamma \mathrm{H} 2 \mathrm{AX}$ foci in cells containing shSIM2 that were treated with $\mathrm{HU}$
(Fig. 4). This finding is likely due to an increase in unresolved stalled replication forks and an increase in dsDNA breaks [13].

To further investigate how loss of SIM2 leads to an increase in genomic instability, we next looked at the recruitment of BRCA1, a factor that has been shown to be crucial for the stabilization of stalled replication forks [10]. Interestingly, we observed an increase in BRCA1 recruitment in response to $24 \mathrm{~h}$ of $0.5 \mathrm{mM} \mathrm{HU}$ treatment (Fig. 4). Previous reports have demonstrated that increased levels of BRCA1 can be observed with loss of 53BP1 [26]. As such, we next assessed the recruitment of p53BP1 to sites of replication stress and found that loss of SIM2 had no effect on p53BP1 recruitment (Fig. 4).

Having seen an increase in BRCA1 recruitment without observing a change in p53BP1, we hypothesized that loss of SIM2 impedes processes downstream of BRCA1, and thus leads to an increase in BRCA1 levels as more BRCA1 peptides are recruited with few replication lesions being resolved. To continue to investigate where SIM2s resides in this pathway, we next looked at the recruitment of RPA to stalled replication forks, as it coats ssDNA and protects it for nucleolytic enzymes as well as prevents the formation of secondary DNA structures that would impede the repair process [27-29]. Interestingly, we observed an increase in the number of RPA- 


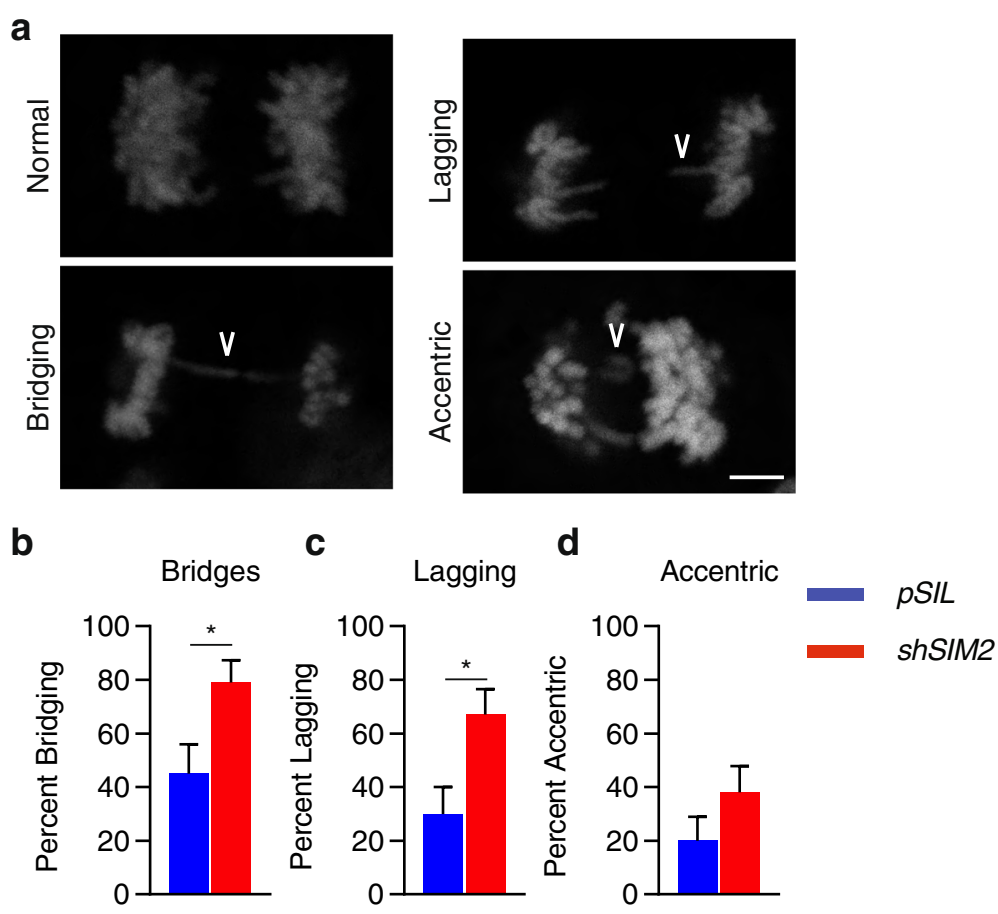

Fig. 3 Loss of SIM2s disrupts DNA replication. a Representative images showing normal, bridging, lagging, and acentric chromosomes during mitosis. MCF7-shSIM2 and MCF7-pSIL cells were synchronized and fixed during anaphase before being analyzed for the presence of $\mathbf{b}$ bridging strands, c lagging strands, and $\mathbf{d}$ acentric chromosomes. Likelihood ratio and Pearson's chi-squared tests were performed to test correlations. $n=$ 20. Scale bar, $10 \mu \mathrm{m}$. ${ }^{*} p$ value $<0.05$

positive foci within MCF7 cells containing shSIM2 after $24 \mathrm{~h}$ of treatment with $0.5 \mathrm{mM} \mathrm{HU}$ (Fig. 4).

Finally, having previously observed that loss of SIM2 leads to a decrease in the formation of RAD51 subnuclear foci in response to ionizing radiation, we tested whether loss of SIM2 also impeded RAD51 recruitment in response to replication stress. In contrast to other factors tested, loss of SIM2 led to a significant decrease in RAD51 foci formation in MCF7 cells treated with 0.5 $\mathrm{mM} \mathrm{HU}$ for $24 \mathrm{~h}$ (Fig. 4).

\section{SIM2s is necessary for RAD51 recruitment in response to} genotoxic stress in primary mammary epithelial cells

To confirm our finding that RAD51 is reduced in cells lacking SIM2s, we utilized a mammary tissuespecific conditional Sim2 knockout mouse, which was generated via a "floxed" $\operatorname{Sim} 2^{f l / f l}$ allele. $\operatorname{Sim} 2$ is conditionally deleted for the duration of lactation by crossing Sim2 $2^{f l f l}$ mice with $\mathrm{Wap}^{\mathrm{Cre} /+}$ mice, which express Cre recombinase under the control of the whey acidic protein (Wap) promoter. Wap is specifically expressed in mammary alveolar epithelial cells from mid-pregnancy through lactation, and thus allows for conditional knockout of Sim2. To visualize Cre recombinase activity, $\mathrm{Wap}^{\mathrm{Cre} /+} ; \operatorname{Sim} 2^{f l / f l}\left(\operatorname{Sim} 2^{f l / f l}\right)$ and $\mathrm{Wap}^{\mathrm{Cre} /+} ; \mathrm{Sim}^{+/+}$(control) mice were genetically tagged with Gt (ROSA)26Sor ${ }^{\text {tm4(ACTB-tdTomato,-EGFP)luo/ }}$ J (mTmG) [30]. Confirmation of efficient loss of the $\operatorname{Sim} 2 s$ locus after pregnancy was visualized in tissue sections using immunofluorescence and was confirmed via RT-qPCR (Fig. 5a, b). Primary mammary epithelial cells (MEC) were isolated from mice during late pregnancy (day 18) and treated with $0.5 \mathrm{mM} \mathrm{HU}$ or DMSO for $24 \mathrm{~h}$ prior to immunostaining for RAD51. As we observed in MCF7 cells, loss of SIM2s led to a significant reduction in RAD51 foci in cells treated with $\mathrm{HU}$ (Fig. 5c).

\section{Loss of SIM2s increases $\mathrm{yH} 2 \mathrm{AX}$ levels in mammary tissue} With a significant decrease in RAD51 with the loss of SIM2s, we hypothesized that prolonged absence of SIM2s would lead to an increase in genomic instability, resulting in elevated levels of DNA damage. To test this, we isolated the fourth inguinal mammary glands of $\operatorname{Sim} 2^{f l f l}$ and control mice at lactation day 18, allowing MECs to progress through pregnancy and peak lactation; two stages that metabolically stress the mammary tissue and result in the elevation of factors associated with HR [31]. Sections were then probed for $\gamma \mathrm{H} 2 \mathrm{AX}$. Loss of SIM2 resulted in significantly higher intensities of $\gamma \mathrm{H} 2 \mathrm{AX}$, suggesting that decreased levels of SIM2s result in elevated levels of genomic instability (Fig. 5d). 


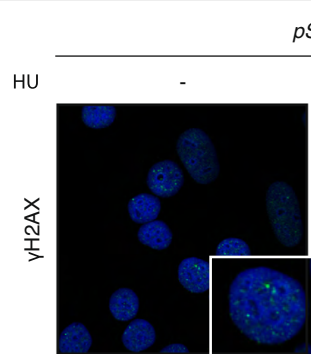
$p S I L$
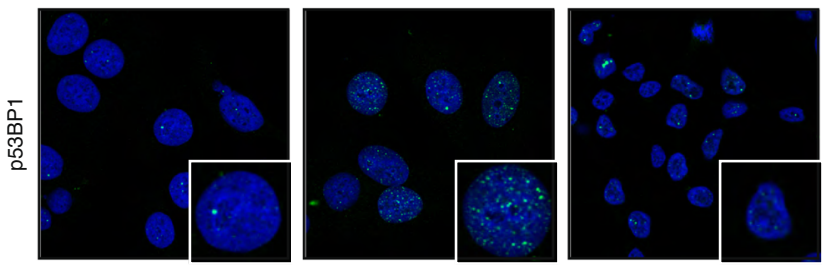

shSIM2
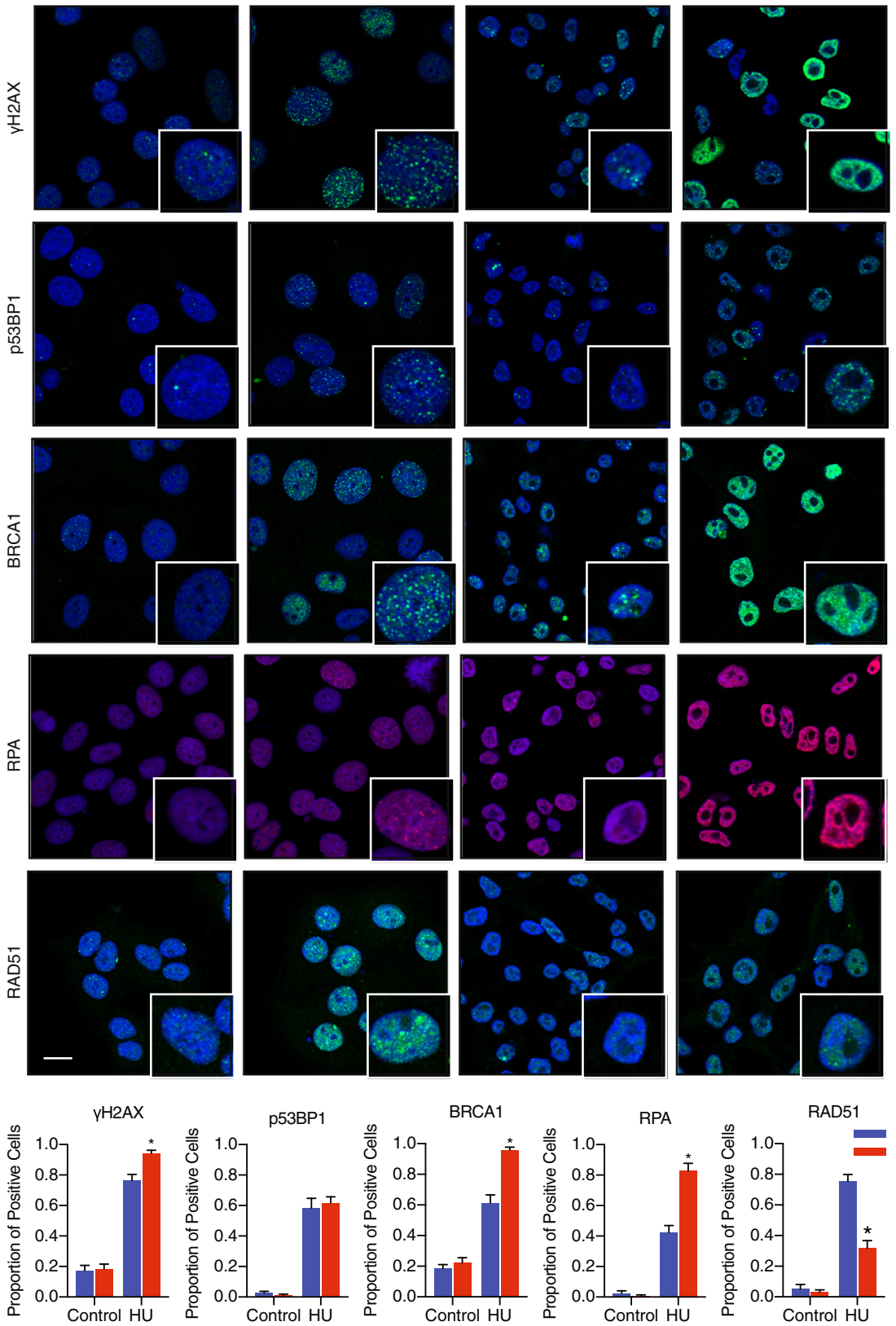

Fig. 4 Loss of SIM2s leads to a decrease in RAD51 foci MCF7 cells. MCF7 cells containing shSIM2 or pSIL were treated with $0.5 \mathrm{mM} \mathrm{HU}$, fixed $24 \mathrm{~h}$ later, and finally probed with the indicated antibody. Cells containing 10 or more foci were considered to be positive for the factors indicated as has previously been demonstrated [13]. Scale bars, $10 \mu \mathrm{m}$. Values indicate the mean \pm SE with $n \geq 100$ cells. Student's $t$ test was performed to test significance. ${ }^{*} p$ value $<0.05$

SIM2s interacts with RAD51 and is necessary for RAD51 binding to the chromosome

It has been established that RAD51 translocates to the nucleus before binding to dsDNA breaks in response to DNA damage [32]. To test where in this process loss of SIM2s interferes with RAD51 loading, we isolated cytoplasmic, soluble nucleus, and insoluble nuclear (chromatin) fractions from MCF7-shSIM2 and MCF7pSIL cells that had been treated with DMSO or $0.5 \mathrm{mM}$ HU for $24 \mathrm{~h}$ (Fig. 6a). Counterintuitive to the decrease in RAD51 foci we observed in response to DNA damage in the shSIM2 cells, we detected an increase in RAD51 levels in the cytoplasm, both basally and with treatment of HU. We also observed no change in the ability of 


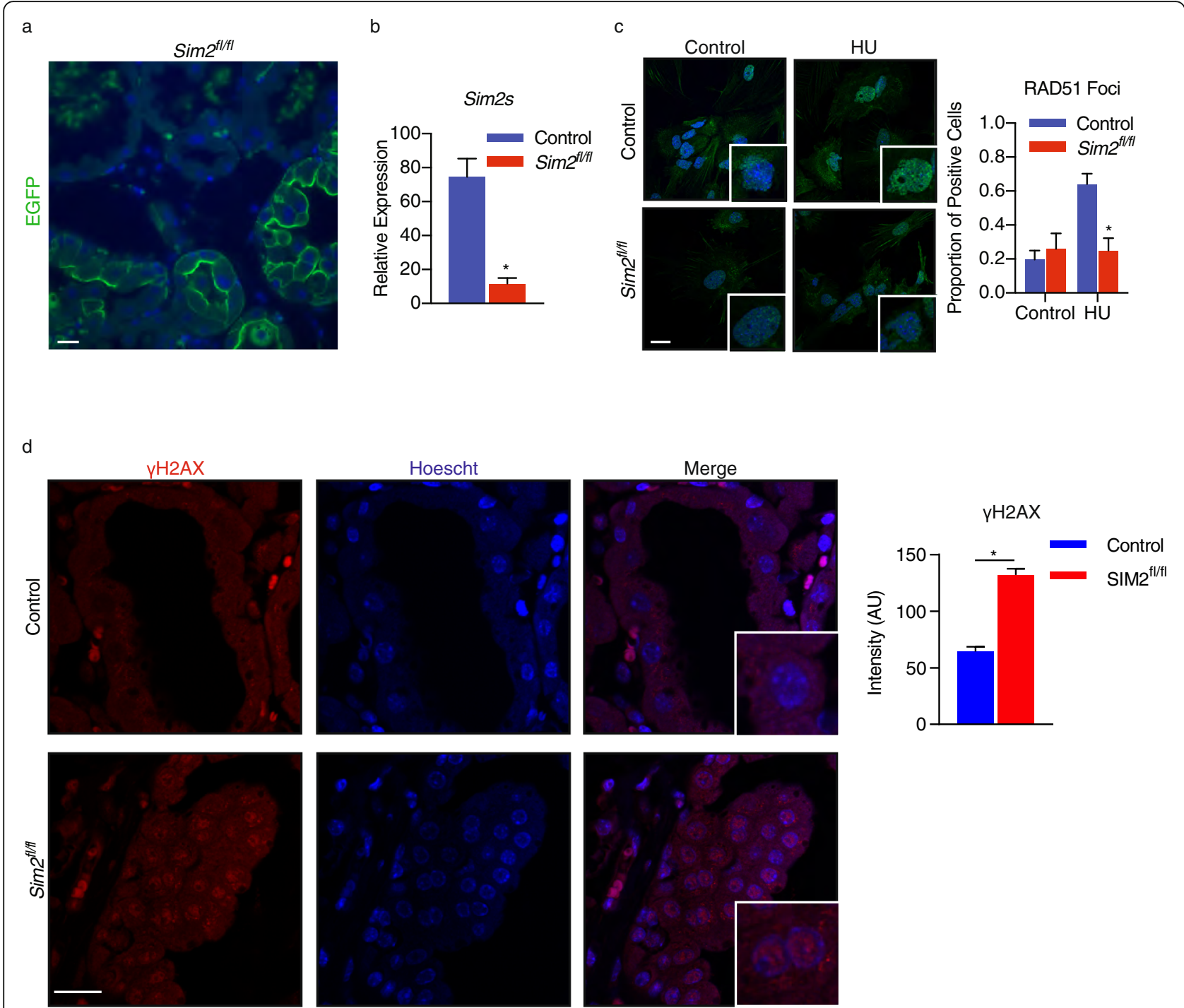

Fig. 5 Loss of SIM2s in a mouse model decreases RAD51 recruitment and increases genomic instability. a Recombination of the SIM2 locus was confirmed in late-stage pregnant mice by the presence of eGFP. Scale bars, $20 \mu \mathrm{m}$. b RNA isolated from mammary glands of control or SIM2 $2^{\mathrm{fl} / \mathrm{fl}}$ mice was analyzed via RT-qPCR for the presence of $\operatorname{sim} 2 s$ mRNA. c MECs isolated from control and late-stage pregnancy SIM2 ${ }^{\mathrm{fl} / \mathrm{fl}}$ mice were treated with $0.5 \mathrm{mM} \mathrm{HU}$ for $24 \mathrm{~h}$ before being assessed for the presence of RAD51 foci. Cells containing 10 or more foci were considered to be positive for the factors indicated as has previously been demonstrated [13]. Scale bars, $10 \mu \mathrm{m}$. $\mathbf{d}$ Mammary glands were collected from lactating $\mathrm{SIM}^{\mathrm{fl} / \mathrm{fl}}$ and control mice and assessed for the presence of $\mathrm{\gamma H} 2 \mathrm{aX}$. Quantification of $\mathrm{\gamma H} 2 \mathrm{aX}$ is nuclear $\mathrm{\gamma H} 2 \mathrm{aX}$ intensity minus background. Scale bars, $20 \mu \mathrm{m}$. Values indicate the mean \pm SE with $n=3$. Student's $t$ test was performed to test significance. ${ }^{*} p$ value $<0.05$

RAD51 to translocate to the nucleus (Fig. 6a). However, loss of SIM2s led to a significant decrease in the levels of RAD51 found in the insoluble/chromatin fraction of the nucleus (Fig. 6a).

Having previously shown that SIM2s interact with BRCA1, we next hypothesized that SIM2s may be necessary for RAD51 to interact with other proteins within the repairosome [13]. However, MCF7 cells containing shSIM2 that were treated with $0.5 \mathrm{mM}$ HU did not show a significant decrease in the ability of RAD51 to bind to BRCA1, as observed through immunoprecipitation of BRCA1 (Fig. 6b). Interestingly, there appears to be an increase in BRCA1 protein levels in cells containing shSIM2 (Fig. 6b). This finding is not typically observed with loss of RAD51 and may indicate a secondary pathway by which SIM2 regulates DNA-damage repair [33].

Based on this finding, we next hypothesized that SIM2s may directly interact with RAD51. As no previous studies show the kinetics of SIM2s in response to HU treatment, we first analyzed SIM2 levels in response to $0.5 \mathrm{mM} \mathrm{HU}$ treatment over time. In order to facilitate this process, $p L P C X-S I M 2 s-F L A G$ was stably transduced into MCF7 cells, which resulted in cell senescence and death (data not shown). As such, $p L P C X$-SIM2s-FLAG 


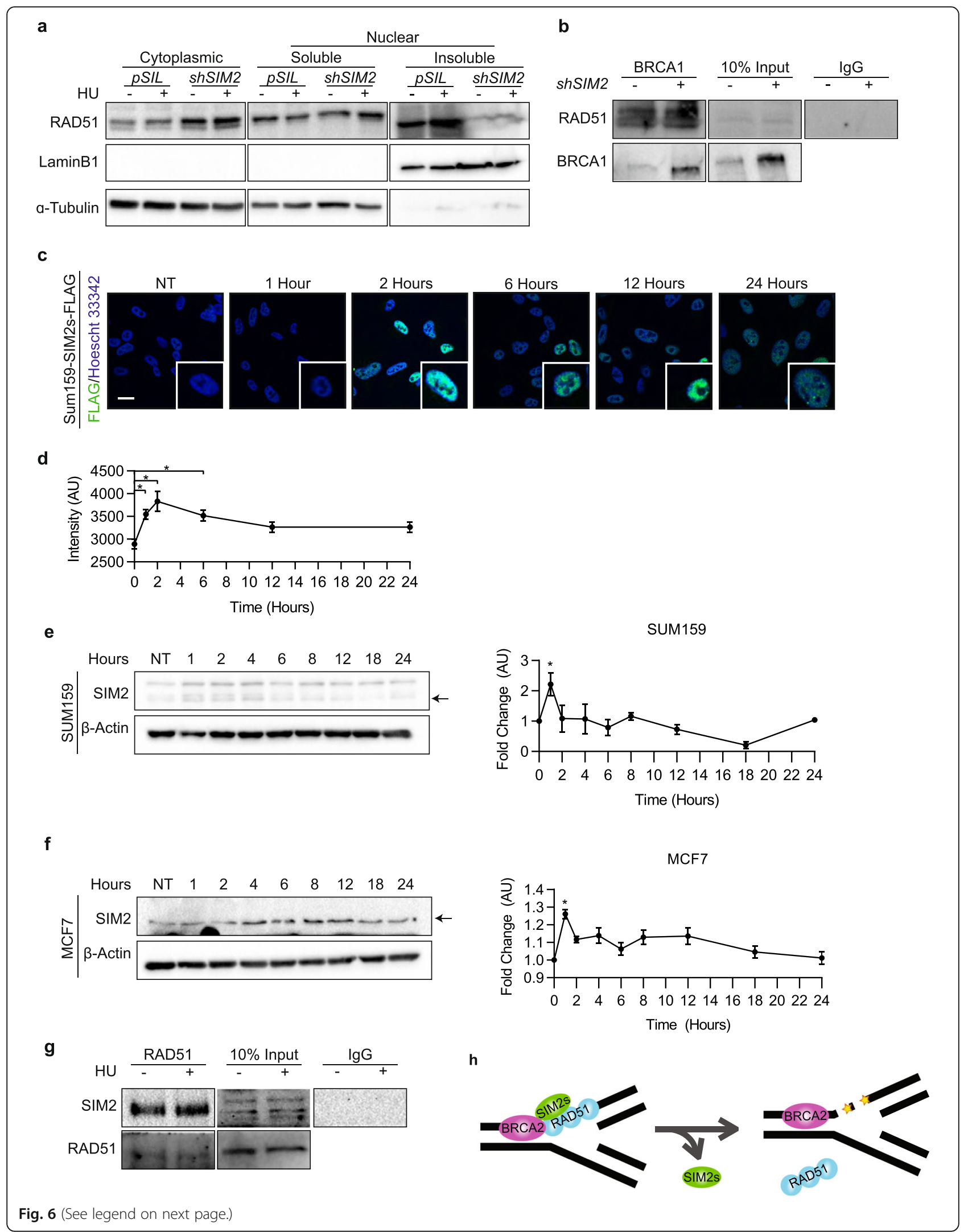


(See figure on previous page.)

Fig. 6 SIM2s interacts with RAD51 and is necessary for subnuclear RAD51 localization. a MCF7-shSIM2 and MCF7-pSIL cells were treated with DMSO or $0.5 \mathrm{mM} \mathrm{HU}$ for $24 \mathrm{~h}$ and then fractionated before being probed for RAD51. $\mathrm{a}$-Tubulin and LaminB1 were used as loading controls to verify efficient separation of fractions. b MCF7-shSIM2 and MCF7-pSIL cells were treated with $0.5 \mathrm{mM} \mathrm{HU}$ and harvested $2 \mathrm{~h}$ later. BRCA1 was immunoprecipitated and lysates were probed for the indicated proteins. c Stabilization and localization of SIM2s was assessed in SUM159-SIM2sFLAG treated with $0.5 \mathrm{mM} \mathrm{HU}$ and fixed at the indicated timepoints before being probed for FLAG. $\mathbf{d}$ Quantification of nuclear FLAG from c. e, $\mathbf{f}$ Western blot analysis of SIM2 stabilization in e SUM159-SIM2s-FLAG and $\mathbf{f}$ MCF7 cells in response to $0.5 \mathrm{mM}$ HU treatment. Arrow indicates predicted molecular weight of SIM2s. Quantification is the ratio of SIM2s to $\beta$-actin. $\mathbf{g}$ RAD51 was immunoprecipitated in MCF7 cells after $2 \mathrm{~h}$ of treatment with $\mathrm{HU}$ or DMSO and lysates were probed for the indicated proteins. $\mathbf{h}$ Graphical representation showing fork stabilization in cells containing SIM2s and fork collapse with loss of SIM2s

was then transduced into SUM159 TNBC cancer cell line [13], which endogenously expresses low levels of SIM2 (data not shown). Immunofluorescent analysis of FLAG in SUM159 cells overexpressing SIM2s-FLAG showed an increase in nuclear FLAG after treatment with $0.5 \mathrm{mM} \mathrm{HU}$ (Fig. 6c, d). These findings were also confirmed via western blot analysis in SUM159 and MCF7 cells, where we saw increased levels of SIM2s 24h after treatment with $0.5 \mathrm{mM} \mathrm{HU}$ (Fig. 6e, f). Having shown that SIM2 levels peak $2 \mathrm{~h}$ after treatment with $\mathrm{HU}$, we next immunoprecipitated RAD51 from MCF7 cells treated with DMSO or $\mathrm{HU}$ for $2 \mathrm{~h}$ and probed for SIM2s to test for their interaction. Interestingly, we observed that RAD51 interacts with SIM2s both basally and with HU treatment (Fig. 6g), confirming that SIM2 interacts with the RAD51 complex.

\section{Discussion}

In this study, we have shown that loss of SIM2s sensitizes replication forks to genotoxic stress, leading to an increase in replication fork collapse (Figs. 1 and 2). This coincides with abnormal separation of sister chromatids during mitosis, which results in chromatin fragmentation and aneuploidy (Fig. 3) [7]. These findings parallel those previously observed with BRCA1 mutations, with familial BRCA1/2-associated tumors having a higher instance of DNA deletions and chromosomal translocations than sporadic tumors [34]. The rapid flux in genomic integrity that is observed in BRCA-mutated tumors predisposes them to mutations in TP53, estrogen receptor (ER), progesterone receptor (PR), and ERBB2 (HER2; human epidermal growth factor receptor 2), and thus biases them toward highly invasive, TNBC with a poor clinical prognosis [35].

A mutation in a single BRCA1/2 allele is sufficient to result in carcinogenesis; however, a single functional copy of BRCA1/2 is also sufficient to maintain HR functionality [34]. Thus, BRCA-mutated tumor progression is thought to predominantly occur through loss of heterozygosity (LOH). Yet, the mechanistic pathways underlying $\mathrm{LOH}$ are vague and revolve around accruing DNA damage. More recent studies have shown that replication stress is more sensitive to perturbations in BRCA1 levels than other established BRCA1 roles. More specifically, a mutation in a single copy of BRCA1 is sufficient to reduce replication fork stability [34]. This finding lends support to the notion that although the role BRCA plays in HR is crucial to maintaining genomic fidelity, the initial, and possibly more important increase in genomic instability seen during cancer progression in BRCA-associated tumors could be due to its role in maintaining replication fork stability. The rapid increase in genomic instability observed with $B R C A$ mutations mimics those we see with loss of SIM2s, underpinning its importance in this pathway (Fig. 5).

The direct role SIM2s plays within this pathway remains unknown and requires further investigation. Here, we show that loss of SIM2s does not affect the ability of RAD51 to translocate to the nucleus in response to replication stress (Fig. 6). The ATP hydrolysis activity of RAD51 has drastically decreased during its evolution from RecA (the bacterial RAD51 homolog), allowing RAD51 paralogs to regulate RAD51 binding and unbinding to DNA [36]. RAD51 paralogs form two distinct complexes: RAD51B-RAD51C-RAD51D-XRCC2 (BCDX2 complex) and RAD51C-XRCC3, which require RAD51D and XRCC2 to catalyze RAD51 binding to DNA and the RAD51C-XRCC3 complex to catalyze RAD51 removal [37-40]. The loss of RAD51 foci in response to genotoxic stress with loss of SIM2s suggests that SIM2s may be interacting directly with RAD51 or indirectly acting on RAD51 through interaction/regulation of the BCDX2 complex. Interestingly, in colorectal cancer patients, where high levels of SIM2s are linked to poor prognosis, high levels of XRCC2 are also associated with poor clinical outcome [41]. This parallel may suggest that SIM2s is involved in the regulation of the BCDX2 complex.

In previous publications, we have demonstrated that loss of SIM2s in a xenograft model results in an EMT, characterized by decreased levels of E-Cadherin, increased activity of matrix- metalloproteinases (MMPs), and increased invasion and migration potential [13]. However, loss of SIM2s alone in a normal mammary gland is not sufficient to instigate tumor initiation (data not shown). It is not uncommon for tumor-suppressing factors to rely on a secondary mutation to initiate tumor development, and in fact, this trend is also observed in 
$B R C A 1, B R C A 2$, and $R A D 51 C$ mutations [42-44]. Moreover, LOH in TP53 in combination with mutation of any of these genes is sufficient to give rise to tumor cells [42-44]. As mentioned above, this combination results in drastic shift from cellular quiescence and toward TNBC [35].

Due to the strong association between BRCA mutations and early-onset breast carcinogenesis, genetic testing for BRCA1 and BRCA2 mutations has been suggested for individuals with breast cancer under the age of 60 . However, an argument should be made to broaden the scope of genetic testing for individuals with early-onset breast cancer. In these individuals, multigene analysis of factors involved in DDR is warranted based on the correlation of elevated TNBC incidence and mutations in BARD1, BRIP1, PALB2, and the RAD51 paralogs RAD51C and RAD51D [45]. The definitive role of RAD51 in alleviating replication stress, protecting damaged DNA from nucleases, and promoting genomic stability has long been established [46]. However, due to the embryonic lethality of $R A D 51^{-/-}$and knockouts of RAD51 paralogs, very little progress has been made toward understanding the regulation of RAD51 [47]. For example, RAD51C and XRCC3 have been known to play a role in HR for decades, but, due to the difficulty in researching genes that are critical for development, their involvement in replication fork restart has only recently been discovered [47]. This has also prevented the development of treatments directly targeting these mutations.

A unique therapeutic advantage of cancers with mutations in proteins involved in HR is their sensitivity to synthetic lethality treatments [48]. Two leading classes of drugs that have shown promising results are the platinum salts and PARPi. In fact, the PARPi Olaparib (AZD2281) has only recently gained approval by the Unites States Food and Drug Administration for use in BRCA-associated tumors [49]. These treatments aim to create dsDNA breaks either through crosslinking DNA, as in the platinum salts, or through the inhibition of PARP release from DNA, which forces DNA breaks during replication. These breaks could easily be repaired by cells with functional DDR but are lethal to cells with dysfunctional DDR pathways.

Although currently only approved for the treatment of BRCA-associated tumors, the efficacy of synthetic lethality treatments in cells with mutations in SIM2s, XRCC2, $R A D 51$, and $R A D 51 C$ has been shown by our lab and others [13, 41, 50]. Interestingly, RAD51 levels can be used as an indicator of the efficacy of PARPi treatments in breast cancer [51]. Moreover, BRCA-mutated tumors that express low levels of RAD51, and thus have low recombinase activity, have been shown to predict treatment efficacy [52-54]. This finding highlights the importance of fully understanding the factors involved in the regulation of HR and continuing to identify novel elements within this pathway, such as SIM2s. These efforts will ultimately lead to a better understanding of the intricacies involved in replication stress and improve patient outcomes.

\section{Conclusions}

In summary, these findings support a role for SIM2s in the prevention of breast cancer progression through its integral part in maintaining genomic stability through DNA-damage repair and the resolution of replication stress. It has previously been established that dysregulation of RAD51 recruitment to sites of DDR is associated with a highly aggressive phenotype which can include lymph node recruitment, basal-like phenotypes, and TNBC status [55]. Contrary to previous reports, this association has been found to not only be due to the role RAD51 plays in DNA-damage repair, but also, more importantly, its pivotal role in the stabilization and resolution of stalled replication forks. Failure of a cell to sufficiently protect and resolve replication stress leads to a rampant increase in chromosomal abnormalities and cancer heterogeneity [56]. Thus, the characterization of the pathways associated with the maintenance of replication stability should be of great importance. In the data presented here, we have demonstrated that SIM2s is necessary for RAD51 to be loaded onto sites of replication stress, and in its absence, RAD51 is not recruited, leading to replication fork collapse.

\section{Supplementary information}

Supplementary information accompanies this paper at https://doi.org/10. 1186/s13058-019-1207-z.

Additional file: 1 Figure S1. Loss of SIM2s does not affect replicationfork restart time. (a-b) Visualization of CldU tract lengths from MCF7shSIM2 and MCF7-pSIL cells treated with DMSO or $10 \mathrm{mM} \mathrm{HU}$. Table S1. Antibody List.

\section{Abbreviations}

ATCC: American Type Culture Collection; ATM: Ataxia telangiectasia mutated; CldU: 5-Chloro-2'-deoxyuridine; DDR: DNA-damage repair; EMT: Epithelial mesenchymal transition; ER: Estrogen receptor; ERBB2: HER2; human epidermal growth factor receptor 2; HR: Homologous recombination; HU: Hydroxyurea; IdU: 5-lodo-2'-deoxyuridine; IF: Immunofluorescence; LOH: Loss of heterozygosity; MEC: Mammary epithelial cell; MMP: Matrix metalloproteinases; PARPi: PARP inhibitor; PR: Progesterone receptor; RTqPCR: Real-time qPCR; SIM2s: Singleminded-2s; TNBC: Triple-negative breast cancer; Wap: Whey acidic protein

\section{Acknowledgements}

We would like to thank the Texas A\&M University College of Veterinary Medicine \& Biomedical Sciences Image Analysis Laboratory, supported by NIH-NCRR (1S10RR22532-01) grant, for confocal microscopy and image analysis. We would also like to thank the Histology Core Facility at Texas A\&M University College of Veterinary Medicine \& Biomedical Sciences for tissue preparation. 


\section{Authors' contributions}

SJP and WP conceived the studies. SJP wrote the manuscript. SJP, JE, and RB conducted statistical analysis. RB, JE, and S.JP did image acquisition and analysis. JE verified the mouse model and acquired tissue samples. S.JP and BMW set up DNA combing experiments. WP and MR provided resources and contributed to data analysis. SJP, JE, MR, and WP contributed to the editing of the manuscript and all authors read and approved the final manuscript.

\section{Funding}

National Cancer Institute R21CA190941 (WP); R01HD083952 (CO-PI WP, MR).

\section{Availability of data and materials}

The datasets used and/or analyzed during the current study are available from the corresponding author on reasonable request.

\section{Ethics approval and consent to participate}

Animal studies were approved by the Texas A\&M University Laboratory Animal Care Committee in accordance with the IACUC guidelines.

\section{Consent for publication}

Not applicable.

\section{Competing interests}

The authors declare that they have no competing interests.

\section{Author details}

'Department of Integrative Biosciences, College of Veterinary Medicine, Texas A\&M University, College Station, TX 77843, USA. ${ }^{2}$ Department of Molecular and Cellular Medicine, Texas A\&M University, College Station, TX 77843, USA. ${ }^{3}$ Present Address: Veterinary Integrative Biosciences, Texas A\&M University, College of Veterinary Medicine, College Station, TX 77843, USA.

\section{Received: 9 May 2019 Accepted: 1 October 2019}

\section{Published online: 27 November 2019}

\section{References}

1. SEER Cancer statistics review, 1975-2014, https://seer.cancer.gov/csr/1 975_2014/. Accecessed Feb 42019.

2. Kuchenbaecker KB, Hopper JL, Barnes DR, Phillips KA, Mooij TM, Roos-Blom MJ, Jervis S, van Leeuwen FE, Milne RL, Andrieu N, et al. Risks of breast, ovarian, and contralateral breast cancer for BRCA1 and BRCA2 mutation carriers. JAMA. 2017;317(23):2402-16.

3. Peshkin BN, Alabek ML, Isaacs C. BRCA1/2 mutations and triple negative breast cancers. Breast Dis. 2010;32(1-2):25-33.

4. Greenup R, Buchanan A, Lorizio W, Rhoads K, Chan S, Leedom T, King R, McLennan J, Crawford B, Kelly Marcom P, et al. Prevalence of BRCA mutations among women with triple-negative breast cancer (TNBC) in a genetic counseling cohort. Ann Surg Oncol. 2013;20(10):3254-8.

5. Pathania S, Nguyen J, Hill SJ, Scully R, Adelmant GO, Marto JA, Feunteun J, Livingston DM. BRCA1 is required for postreplication repair after UV-induced DNA damage. Mol Cell. 2011;44(2):235-51.

6. Zeman MK, Cimprich KA. Causes and consequences of replication stress. Nat Cell Biol. 2014;16(1):2-9.

7. Petermann E, Orta ML, Issaeva N, Schultz N, Helleday T. Hydroxyureastalled replication forks become progressively inactivated and require two different RAD51-mediated pathways for restart and repair. Mol Cell. 2010;37(4):492-502.

8. Lundin C, Erixon K, Arnaudeau C, Schultz N, Jenssen D, Meuth M, Helleday T. Different roles for nonhomologous end joining and homologous recombination following replication arrest in mammalian cells. Mol Cell Biol. 2002;22(16):5869-78.

9. Helleday T. Pathways for mitotic homologous recombination in mammalian cells. Mutat Res. 2003;532(1-2):103-15.

10. Zhang J. The role of BRCA1 in homologous recombination repair in response to replication stress: significance in tumorigenesis and cancer therapy. Cell Biosci. 2013;3(1):11.

11. Laulier C, Cheng A, Stark JM. The relative efficiency of homology-directed repair has distinct effects on proper anaphase chromosome separation. Nucleic Acids Res. 2011;39(14):5935-44.

12. Nitiss JL. DNA topoisomerase II and its growing repertoire of biological functions. Nat Rev Cancer. 2009;9(5):327-37.
13. Pearson SJ, Roy Sarkar T, McQueen CM, Elswood J, Schmitt EE, Wall SW, Scribner KC, Wyatt G, Barhoumi R, Behbod F, et al. ATM-dependent activation of SIM2s regulates homologous recombination and epithelialmesenchymal transition. Oncogene. 2019;38(14):2611-26.

14. Laffin B, Wellberg E, Kwak HI, Burghardt RC, Metz RP, Gustafson T, Schedin P, Porter WW. Loss of singleminded-2s in the mouse mammary gland induces an epithelial-mesenchymal transition associated with up-regulation of slug and matrix metalloprotease 2. Mol Cell Biol. 2008;28(6):1936-46.

15. Gustafson TL, Wellberg E, Laffin B, Schilling L, Metz RP, Zahnow CA, Porter WW. Ha-Ras transformation of MCF10A cells leads to repression of Singleminded-2s through NOTCH and C/EBPbeta. Oncogene. 2009;28(12):1561-8.

16. Kwak HI, Gustafson T, Metz RP, Laffin B, Schedin P, Porter WW. Inhibition of breast cancer growth and invasion by single-minded 2s. Carcinogenesis. 2007;28(2):259-66.

17. Scribner KC, Behbod F, Porter WW. Regulation of DCIS to invasive breast cancer progression by Singleminded-2s (SIM2s). Oncogene. 2013;32(21):2631-9.

18. Metz RP, Kwak HI, Gustafson T, Laffin B, Porter WW. Differential transcriptional regulation by mouse single-minded 2s. J Biol Chem. 2006;281(16):10839-48.

19. Wellberg E, Metz RP, Parker C, Porter WW. The bHLH/PAS transcription factor singleminded $2 \mathrm{~s}$ promotes mammary gland lactogenic differentiation. Development. 2010;137(6):945-52.

20. Scribner KC, Wellberg EA, Metz RP, Porter WW. Singleminded-2s (Sim2s) promotes delayed involution of the mouse mammary gland through suppression of Stat3 and NFkappaB. Mol Endocrinol. 2011;25(4):635-44.

21. Parra I, Windle B. High resolution visual mapping of stretched DNA by fluorescent hybridization. Nat Genet. 1993:5(1):17-21.

22. Mendez J, Stillman B. Chromatin association of human origin recognition complex, cdc6, and minichromosome maintenance proteins during the cell cycle: assembly of prereplication complexes in late mitosis. Mol Cell Biol. 2000;20(22):8602-12.

23. He J, Kang $X$, Yin Y, Chao KS, Shen WH. PTEN regulates DNA replication progression and stalled fork recovery. Nat Commun. 2015;6:7620.

24. Gagou ME, Zuazua-Villar P, Meuth M. Enhanced H2AX phosphorylation, DNA replication fork arrest, and cell death in the absence of Chk1. Mol Biol Cell. 2010;21(5):739-52.

25. Her J, Ray C, Altshuler J, Zheng H, Bunting SF. 53BP1 mediates ATR-Chk1 signaling and protects replication forks under conditions of replication stress. Mol Cell Biol. 2018;38(8):e00472-17.

26. Bouwman P, Aly A, Escandell JM, Pieterse M, Bartkova J, van der Gulden $H$, Hiddingh S, Thanasoula M, Kulkarni A, Yang Q, et al. 53BP1 loss rescues BRCA1 deficiency and is associated with triple-negative and BRCA-mutated breast cancers. Nat Struct Mol Biol. 2010;17(6):688-95.

27. Bochkareva E, Korolev S, Lees-Miller SP, Bochkarev A. Structure of the RPA trimerization core and its role in the multistep DNA-binding mechanism of RPA. EMBO J. 2002;21 (7):1855-63.

28. Chen $H$, Lisby M, Symington LS. RPA coordinates DNA end resection and prevents formation of DNA hairpins. Mol Cell. 2013;50(4):589-600.

29. Zou L, Elledge SJ. Sensing DNA damage through ATRIP recognition of RPAssDNA complexes. Science. 2003;300(5625):1542-8.

30. Muzumdar MD, Tasic B, Miyamichi K, Li L, Luo L. A global doublefluorescent Cre reporter mouse. Genesis. 2007;45(9):593-605.

31. Eilon T, Barash I. Forced activation of Stat5 subjects mammary epithelial cells to DNA damage and preferential induction of the cellular response mechanism during proliferation. J Cell Physiol. 2011;226(3):616-26.

32. Gildemeister OS, Sage JM, Knight KL. Cellular redistribution of Rad51 in response to DNA damage: novel role for Rad51C. J Biol Chem. 2009:284(46):31945-52.

33. Kaplan AR, Gueble SE, Liu Y, Oeck S, Kim H, Yun Z, Glazer PM. Cediranib suppresses homology-directed DNA repair through down-regulation of BRCA1/2 and RAD51. Sci Transl Med. 2019;11(492):e0207399.

34. Pathania S, Bade S, Le Guillou M, Burke K, Reed R, Bowman-Colin C, Su Y, Ting DT, Polyak K, Richardson AL, et al. BRCA1 haploinsufficiency for replication stress suppression in primary cells. Nat Commun. 2014;5:5496.

35. Turner $\mathrm{N}$, Tutt $\mathrm{A}$, Ashworth A. Hallmarks of 'BRCAness' in sporadic cancers. Nat Rev Cancer. 2004;4(10):814-9.

36. Tombline G, Fishel R. Biochemical characterization of the human RAD51 protein. I ATP Hydrolysis J Biol Chem. 2002;277(17):14417-25.

37. Liu N, Schild D, Thelen MP, Thompson LH. Involvement of Rad51C in two distinct protein complexes of Rad51 paralogs in human cells. Nucleic Acids Res. 2002:30(4):1009-15.

38. Masson JY, Tarsounas MC, Stasiak AZ, Stasiak A, Shah R, Mcllwraith MJ, Benson FE, West SC. Identification and purification of two distinct complexes containing the five RAD51 paralogs. Genes Dev. 2001;15(24):3296-307. 
39. Liu Y, Tarsounas M, O'Regan P, West SC. Role of RAD51C and XRCC3 in genetic recombination and DNA repair. J Biol Chem. 2007;282(3):1973-9.

40. Kurumizaka H, Ikawa S, Nakada M, Enomoto R, Kagawa W, Kinebuchi T, Yamazoe M, Yokoyama S, Shibata T. Homologous pairing and ring and filament structure formation activities of the human Xrcc2*Rad51D complex. J Biol Chem. 2002;277(16):14315-20.

41. Xu K, Song X, Chen Z, Qin C, He Y, Zhan W. XRCC2 promotes colorectal cancer cell growth, regulates cell cycle progression, and apoptosis. Medicine (Baltimore). 2014;93(28):e294.

42. Liu X, Holstege H, van der Gulden H, Treur-Mulder M, Zevenhoven J, Velds A, Kerkhoven RM, van Vliet MH, Wessels LF, Peterse JL, et al. Somatic loss of BRCA1 and 553 in mice induces mammary tumors with features of human BRCA1-mutated basal-like breast cancer. Proc Natl Acad Sci U S A. 2007; 104(29):12111-6

43. Cheung AM, Elia A, Tsao MS, Done S, Wagner KU, Hennighausen L, Hakem R, Mak TW. Brca2 deficiency does not impair mammary epithelium development but promotes mammary adenocarcinoma formation in p53(+/-) mutant mice. Cancer Res. 2004;64(6):1959-65.

44. Kuznetsov SG, Haines DC, Martin BK, Sharan SK. Loss of Rad51c leads to embryonic lethality and modulation of Trp53-dependent tumorigenesis in mice. Cancer Res. 2009;69(3):863-72.

45. Shimelis H, LaDuca H, Hu C, Hart SN, Na J, Thomas A, Akinhanmi M, Moore RM, Brauch H, Cox A, et al. Triple-negative breast cancer risk genes identified by multigene hereditary cancer panel testing. J Natl Cancer Inst. 2018;110(8):855-62.

46. Hashimoto Y, Ray Chaudhuri A, Lopes M, Costanzo V. Rad51 protects nascent DNA from Mre11-dependent degradation and promotes continuous DNA synthesis. Nat Struct Mol Biol. 2010;17(11):1305-11.

47. Sullivan MR, Bernstein KA. RAD-ical new insights into RAD51 regulation. Genes (Basel). 2018;9(12):629.

48. Morales J, Li L, Fattah FJ, Dong Y, Bey EA, Patel M, Gao J, Boothman DA. Review of poly (ADP-ribose) polymerase (PARP) mechanisms of action and rationale for targeting in cancer and other diseases. Crit Rev Eukaryot Gene Expr. 2014;24(1):15-28.

49. Ledermann J, Harter P, Gourley C, Friedlander M, Vergote I, Rustin G, Scott C, Meier W, Shapira-Frommer R, Safra T, et al. Olaparib maintenance therapy in platinum-sensitive relapsed ovarian cancer. N Engl J Med. 2012;366(15):1382-92.

50. Min A, Im SA, Yoon YK, Song SH, Nam HJ, Hur HS, Kim HP, Lee KH, Han SW, Oh DY, et al. RAD51C-deficient cancer cells are highly sensitive to the PARP inhibitor olaparib. Mol Cancer Ther. 2013;12(6):865-77.

51. Cruz C, Castroviejo-Bermejo M, Gutierrez-Enriquez S, Llop-Guevara A, Ibrahim YH, Gris-Oliver A, Bonache S, Morancho B, Bruna A, Rueda OM, et al. RAD51 foci as a functional biomarker of homologous recombination repair and PARP inhibitor resistance in germline BRCA-mutated breast cancer. Ann Oncol. 2018;29(5):1203-10.

52. Graeser M, McCarthy A, Lord CJ, Savage K, Hills M, Salter J, Orr N, Parton M, Smith IE, Reis-Filho JS, et al. A marker of homologous recombination predicts pathologic complete response to neoadjuvant chemotherapy in primary breast cancer. Clin Cancer Res. 2010;16(24):6159-68.

53. Murata S, Zhang C, Finch N, Zhang K, Campo L, Breuer EK. Predictors and modulators of synthetic lethality: an update on PARP inhibitors and personalized medicine. Biomed Res Int. 2016;2016:2346585.

54. Maacke H, Opitz S, Jost K, Hamdorf W, Henning W, Kruger S, Feller AC, Lopens A, Diedrich K, Schwinger E, et al. Over-expression of wild-type Rad51 correlates with histological grading of invasive ductal breast cancer. Int J Cancer. 2000;88(6):907-13.

55. Alshareeda AT, Negm OH, Aleskandarany MA, Green AR, Nolan C, TigHhe PJ, Madhusudan S, Ellis IO, Rakha EA. Clinical and biological significance of RAD51 expression in breast cancer: a key DNA damage response protein. Breast Cancer Res Treat. 2016;159(1):41-53

56. Burrell RA, McClelland SE, Endesfelder D, Groth P, Weller MC, Shaikh N, Domingo E, Kanu N, Dewhurst SM, Gronroos E, et al. Replication stress links structural and numerical cancer chromosomal instability. Nature. 2013; 494(7438):492-6.

\section{Publisher's Note}

Springer Nature remains neutral with regard to jurisdictional claims in published maps and institutional affiliations.

\section{Ready to submit your research? Choose BMC and benefit from:}

- fast, convenient online submission

- thorough peer review by experienced researchers in your field

- rapid publication on acceptance

- support for research data, including large and complex data types

- gold Open Access which fosters wider collaboration and increased citations

- maximum visibility for your research: over $100 \mathrm{M}$ website views per year

At BMC, research is always in progress.

Learn more biomedcentral.com/submissions 